\title{
Formação do Psicólogo para Atuar na Educação: Concepções de Coordenadores de Curso
}

\author{
Silvia Maria Cintra da Silva \\ Universidade Federal de Uberlândia, MG, Brasil. \\ Larice Santos Silva \\ Universidade Federal de Uberlândia, MG, Brasil. \\ Flaviana Franco Naves \\ Universidade Federal de Uberlândia, MG, Brasil.
}

\author{
Anabela Almeida Costa e Santos Peretta \\ Universidade Federal de Uberlândia, MG, Brasil. \\ Fabiana Marques Barbosa Nasciutti \\ Universidade Estadual de Campinas, SP, Brasil. \\ Nayara Portilho Lima \\ Universidade Federal de Uberlândia, MG, Brasil.
}

Resumo: Com a implementação das Diretrizes Curriculares Nacionais (DCN) nos cursos de Psicologia em 2004, os projetos pedagógicos passaram a incorporá-las considerando as diferentes condições e especificidades de cada curso. A pesquisa interinstitucional aqui relatada investigou como está ocorrendo a apropriação das DCN pelos cursos de Psicologia, focalizando a ênfase em processos educativos. Em Minas Gerais, foram pesquisadas cinco Instituições de Ensino Superior (IES), sendo três privadas e duas públicas. Abordamos aqui as entrevistas com cinco coordenadores de curso e um ex-coordenador, cuja leitura levou à organização destes eixos de análise: caracterização dos participantes; caracterização do curso de psicologia; diretrizes curriculares nacionais; formação do psicólogo e formação do psicólogo para atuação no campo da educação. Foi constatado que os coordenadores de curso são profissionais que se dividem em múltiplas tarefas e vivenciam inúmeros desafios; são um elemento fundamental para a compreensão e apropriação das DCN no cotidiano dos cursos de Psicologia e importantes mediadores entre este documento, o projeto pedagógico, as atividades docentes e as atividades formativas do psicólogo. A apropriação da função de coordenador é um processo que ocorre no transcorrer do próprio trabalho e, neste sentido, destacamos a necessidade de uma formação continuada que o auxilie a lidar com as diferentes demandas do curso.

Palavras-chave: Coordenadores de Curso, Psicologia Escolar, Formação do Psicólogo, Projeto Político Pedagógico, Psicologia e Educação.

\section{Training of Psychologists to Work in Education - Conceptions of Program Coordinators}

\begin{abstract}
The pedagogical projects of Psychology courses started to incorporate considering their different conditions and specificities - the National Curriculum Guidelines (NCG), after its implementation in 2004. This work reports an inter-institutional research which investigated how the incorporation of NCG is happening within Psychology courses, focusing on the educational processes. Five Higher Education Institutions in Minas Gerais - three public and two private - were surveyed. Interviews with five current Program Coordinators - and a former one - are addressed. A careful reading led to the organization of the following axes: characterization of participants; characterization of the psychology course; national curriculum guidelines; psychologist education; and psychologist training in the field of education. As professionals with multiple tasks that have experienced numerous challenges, coordinators are key actors to understand and incorporate NCG into the everyday of a Psychology course and, at the same time, important mediators of this document, the pedagogical project, the professorial activities, and the psychologist
\end{abstract}


da Silva, Silvia Maria Cintra; Peretta, Anabela Almeida Costa e Santos; Silva, Larice Santos; Nasciutti, Fabiana Marques Barbosa; Naves, Flaviana Franco; Lima, Nayara Portilho (2016). Formação do Psicólogo: Concepçóes de Coordenadores.

educational activities. The appropriation of the role of coordinator is a process that occurs in the course of the work itself and, in this sense, the need for permanent training to help the professional to deal with different demands of the course is highlighted.

Keywords: Program Coordinators, School, Psychologist Education, Political Pedagogical Project, Psychology and Education.

\title{
Formación de Psicólogos para Trabajar en el Ámbito de la Educación - Concepciones de los Coordinadores del Curso
}

\begin{abstract}
Resumen: Con la implementación de las Directrices Curriculares Nacionales (DCN) para los cursos de Psicología en 2004, los proyectos pedagógicos empezaron a incorporarlas considerando las distintas condiciones y características específicas de cada curso. La investigación interinstitucional aquí descrita investigó cómo están utilizando las DCN los cursos de psicología, centrándose en los procesos educativos. Cinco Instituciones de Educación Superior (IES), tres públicas y dos privadas fueron investigadas en Minas Gerais. Abordamos aquí las entrevistas con cinco coordinadores de curso y un ex coordinador; su lectura cuidadosa permitió organizar los ejes de análisis: caracterización de los participantes; caracterización de la carrera de psicología; directrices curriculares nacionales; formación del psicólogo; y formación del psicólogo para trabajar en el campo de la educación. Profesionales que se dividen en varias tareas y experimentan numerosos desafíos, los coordinadores son un elemento clave para la comprensión y el uso de las DCN a diario en los cursos de Psicología, e importantes mediadores entre este documento, el proyecto pedagógico, las actividades de enseñanza y las actividades de formación del psicólogo. La apropiación de la función de coordinador es un proceso que se produce en el curso de la propia función, y en este sentido, destacamos la necesidad de la formación continuada para hacer frente a las diferentes demandas del curso.

Palabras clave: Coordinadores del Curso, Psicología Escolar, Formación del Psicólogo, Proyecto Político Pedagógico, Psicología y Educación.
\end{abstract}

"Eu sou entusiasmado, mas não deslumbrado. Eu acho que tenho um pé na realidade, mas não me desencanto."

Participante da pesquisa

\section{Introdução}

Citamos uma frase mencionada por um dos participantes desta pesquisa como epígrafe porque ela ilustra as condições de trabalho dos coordenadores de curso de Psicologia participantes deste estudo, que mesclam a necessidade de entusiasmo com as intercorrências encontradas no cotidiano da gestão. Desde 2004 os cursos de Psicologia em nosso país iniciaram um processo de reformulações de diferentes naturezas e dimensões que exigiram dos coordenadores tanto a compreensão ampliada sobre as Diretrizes
Curriculares Nacionais (DCN) como o planejamento acerca da sua implementação.

Em meio às proposições e inovações previstas pelas DCN para os cursos de graduação em Psicologia de 2004 (Brasil, 2004), ressalta-se a ruptura com a concepção tradicional de áreas de atuação profissional - Psicologia Clínica, Escolar e Organizacional, por exemplo - na formação, que foram substituídas por ênfases curriculares a serem escolhidas pelos estudantes nos últimos períodos do curso. Em relação ao âmbito educacional, uma das possibilidades de ênfase no supracitado documento está nomeada como "Psicologia e processos educativos".

A pesquisa interinstitucional ${ }^{1}$ "A formação do psicólogo escolar e as diretrizes curriculares em Psi-

1. A pesquisa foi realizada nos Estados de São Paulo, Minas Gerais, Goiás e Rondônia. 
cologia: concepções teóricas, bases metodológicas e atuação profissional"', realizada de 2011 a 2014, teve como objetivo principal analisar a formação dada aos futuros psicólogos nos cursos de Graduação em Psicologia quanto à ênfase nos processos educativos, tendo em vista as DCN. Em Minas Gerais, fizeram parte da pesquisa cinco Instituições de Ensino Superior (IES) sendo três privadas e duas públicas ${ }^{3}$. Nessas instituições foram entrevistados treze professores, cinco coordenadores de curso e um ex-coordenador, 197 estudantes responderam a questionário e foram realizadas análises de documentos oficiais das IES. Neste artigo analisaremos os dados referentes aos coordenadores, personagens fundamentais para a compreensão e a apropriação das DCN no cotidiano do curso de Psicologia, sendo também importantes mediadores entre este documento, o projeto pedagógico, as atividades docentes e as atividades formativas do psicólogo.

Ainda há poucos estudos a respeito da atividade de coordenação de curso, fundamental nos processos de elaboração, execução e acompanhamento do Projeto Pedagógico e que também demanda uma compreensão das atribuições do coordenador em seus aspectos teórico-práticos, tendo em vista o grande número de tarefas e responsabilidades relativas a esta função. Em nosso levantamento, encontramos publicações oriundas principalmente da Administração (Bertucci, \& Moraes, 2003; Camargos, Ferreira, \& Camargos, 2010; Kanan, \& Zanelli, 2004; Marra, \& Melo, 2003; Rangel, 2001; Silva, 2002). Neste artigo pretendemos analisar o pensamento e a ação de coordenadores de curso de Psicologia, considerando algumas especificidades deste cargo tanto no que se refere às suas atribuições específicas como às suas contribuições para a formação do psicólogo escolar.

\section{Formação de psicólogo}

Iniciaremos a discussão a partir de algumas reflexões sobre o Ensino Superior e a formação do psicólogo. Chauí (1999) nos alerta que, na "universidade operacional", a contratação de professores desconsidera o compromisso com a tarefa educativa e o domínio de sua área de conhecimento e, desta maneira, a formação é tratada de forma aligeirada e superficial. Neste sentido, podemos perguntar: Que educação os estudantes devem receber no Ensino Superior? E quanto aos estudantes de Psicologia? E aqueles que se dedicarão ao campo educativo?

Segundo Goergen (2010), considerando que a constituição "de uma sociedade mais justa e democrática depende de indivíduos não só profissionalmente competentes, mas de cidadãos com apurado sentido ético e de responsabilidade social, a universidade, neste caso, deve formar profissionais críticos, autônomos e socialmente responsáveis" (p. 21). Nesse sentido, a preocupação com a formação geral do estudante envolve também o entendimento acerca da realidade do mundo atual, considerando tanto elementos subjetivos como elementos culturais, políticos e econômicos, em uma perspectiva mais ampliada (Pereira, 2010).

Em relação à formação do psicólogo, tem havido uma ampliação de áreas de atuação, oferecendo-se aos alunos a desconstrução de um trabalho majoritariamente clínico e focado em aspectos intrasubjetivos para uma atuação socialmente comprometida, em diversas instituições, pautada em um trabalho coletivo, multidisciplinar e que valoriza a dimensão social no processo de constituição humana. A partir da trajetória da profissão nos últimos 50 anos, Furtado (2012) ressalta a demanda posta pelos Centros de Atenção Psicossocial (CAPS), Centros de Referência da Assistência Social (CRAS), sistema judiciário, ambulatórios, hospitais, esporte, trânsito, "a rede de Atenção Básica à Saúde, os Centros de Referência da Saúde do Trabalhador [...] nas comunicações, as ONGs, e ainda mantemos os tradicionais setores da educação e das organizações" (Furtado, 2012, p. 82) como possibilidades concretas de inserção do psicólogo.

No que se refere à formação do profissional para atuar na área educacional, estudos e pesquisas têm se dedicado a esta temática apontando aspectos importantes para o processo de formação do psicólogo escolar e educacional, como o estágio supervisionado (Asbahr, Martins, \& Mazzolini, 2011; Barbosa, 2013; Guzzo, 2011; Lima, 2012; Silva, Pedro, Silva, Rezende, \& Barbosa, 2013; Silva Neto, 2014), a fundamentação teórico-metodológica (Meira, 2003; Souza, 2009) e a compreensão sobre o fenômeno educativo (Barreto, Calafangel, \& Lima, 2009). Consideramos que todos estes aspectos são imprescindíveis para a constituição do psicólogo

2. Pesquisa financiada pela FAPEMIG - Processo No: APQ-00546-11 Demanda Universal.

3. Por motivos éticos, a localização geográfica das IES não será revelada, para evitar a sua identificação. 


\section{da Silva, Silvia Maria Cintra; Peretta, Anabela Almeida Costa e Santos; Silva, larice Santos; Nasciutti, Fabiana Marques Barbosa; Naves, Flaviana Franco; Lima, Nayara Portilho (2016). Formação do Psicólogo: Concepções de Coordenadores.}

escolar, especialmente no que se refere às especificidades postas pelo campo da educação.

\section{O currículo}

Giroux e Penna (1997) criticam a configuração tradicional dos currículos educacionais que se organizam em uma perspectiva a-histórica, a partir da concepção de que o conhecimento é algo objetivo e externo ao indivíduo. Os autores defendem um novo paradigma, respaldado na chamada nova sociologia do currículo, que solicita desenhos curriculares "que aprofundem a consideração de que o conhecimento é uma construção social. Enfatiza também a necessidade de examinar-se a constelação de interesses econômicos, políticos e sociais que as diferentes formas de conhecimento podem refletir" (pp. 49-50).

Um importante conceito pontuado por Giroux e Penna (1997) é o de currículo oculto, definido pelos autores como: "as normas, valores e crenças não declaradas que são transmitidas aos estudantes através da estrutura subjacente do significado e no conteúdo formal das relações sociais da escola e na vida em sala de aula" (p. 57).

Assim, defendemos que a elaboração do currículo precisa ser pensada considerando-se o perfil do egresso, as condições de formação oferecidas pela Instituição de Ensino Superior (IES), a discussão sobre as DCN, os aspectos éticos e o compromisso social envolvidos tanto na formação do futuro psicólogo quanto nos serviços oferecidos à população brasileira.

\section{Método}

O percurso metodológico compreende o caminho trilhado pelas pesquisadoras durante toda a investigação. Primeiramente foi realizado um levantamento no portal do e-MEC ${ }^{4}$, a fim de verificarmos as IES mineiras que atendiam aos seguintes critérios estabelecidos pelo grupo de pesquisa: experiência consolidada nas áreas de ensino, pesquisa e extensão, implementação das DCN, opção pela Ênfase em Processos Educativos (ou terminologia semelhante) e alunos cursando a referida ênfase. Foram identificadas $57^{5}$ IES que têm o curso de Psicologia em Minas Gerais; dentre elas, selecionamos cinco IES que atendiam aos critérios estabelecidos e se disponibilizaram a participar da pesquisa, sendo três privadas e duas públicas. No âmbito geral da pesquisa, realizamos en- trevistas com 13 professores; cinco coordenadores de curso e um ex-coordenador; 197 questionários foram aplicados junto aos estudantes e realizadas análises de documentos oficiais das IES. Além disso, fizemos a caracterização dos cinco cursos a partir de informações disponibilizadas nos seus respectivos sites, nos Projetos Pedagógicos e no site do e-MEC.

As entrevistas estruturadas, realizadas com coordenadores de cursos de Psicologia, foram audiogravadas, realizadas individualmente nas salas dos coordenadores e buscaram informações relativas a: a) avaliação destes profissionais sobre as Diretrizes Curriculares para os Cursos de Graduação em Psicologia de 2004, considerando-se os aspectos positivos e negativos e as mudanças observadas no que se refere às concepções de formação e de atuação do psicólogo; b) possibilidades de discussão sobre as Diretrizes com os professores que trabalham no curso que coordenam; c) concepções dos docentes a respeito das diretrizes curriculares, na visão dos coordenadores; d) perfil do egresso, considerando a formação do psicólogo para atuar no campo educativo. A análise das entrevistas abrangeu considerações relativas a cinco eixos: a) caracterização dos participantes; b) caracterização do curso de Psicologia; c) diretrizes curriculares nacionais; d) formação do psicólogo e) formação do psicólogo para atuação no campo da educação.

As análises das entrevistas foram realizadas por meio da leitura cuidadosa das transcrições, exercício que contribuiu para elaborar questões norteadoras que guiaram a análise do material supracitado, juntamente com o projeto pedagógico de cada um dos cursos. Os diários de campo escritos pelas pesquisadoras, com as notas pessoais sobre as entrevistas e registros de fatos importantes que não constaram nas audiogravações também compuseram a análise e forma elementos fundamentais no trabalho de campo. Segundo Bogdan e Biklen (1994), o diário de campo engloba reflexões e comentários do pesquisador sobre a investigação, os participantes, o contexto do estudo e impressões gerais suscitadas no transcorrer da pesquisa. Como recurso metodológico, utilizaremos excertos das entrevistas, destacados em itálico, para ilustrar as nossas análises.

Para reiterar a importância do diário de campo, abaixo segue um excerto dos registros de uma das

4. http://emec.mec.gov.br/

5. Estes dados foram encontrados no início da pesquisa, em 2012; em uma busca atual provavelmente essas informações serão diferentes. 
pesquisadoras, anotando a mudança de sua percepção sobre o coordenador de curso entre o primeiro contato telefônico - que lhe causara a impressão de alguém desinteressado no cargo - e o encontro pessoal para realizar a entrevista:

Em nosso primeiro contato ao vivo, me passou outra imagem, a de um coordenador efetivamente cansado, mas muito comprometido com seu curso, conhecedor da história deste, do perfil dos estudantes e também das DCN. Comentei que sentia não ter ligado o gravador para já ter registrado tantas informações importantes!

O percurso metodológico desta pesquisa nos mostrou um panorama sobre como tem se dado a formação do psicólogo para atuar no campo educativo em Minas Gerais. Podemos dizer que este cenário acadêmico mostrou-se tão diverso quanto as paisagens mineiras pelas quais transitamos.

\section{Resultados e discussão}

\section{Caracterização dos participantes}

Em relação ao tempo no cargo, havia um coordenador que estava há dez meses na função, já o entrevistado com maior tempo de trabalho estava no cargo há sete anos. Entre eles, apenas um era ex-aluno da instituição. No que tange à titulação, três são doutores e dois mestres. Dois dos entrevistados ocuparam o cargo com pouco tempo de casa, menos de um ano; um deles havia assumido a função na época da realização da entrevista. Somente um participante estava em seu segundo mandato como coordenador de curso ${ }^{6}$.

Entre os cinco coordenadores, encontramos apenas uma mulher. A maciça presença feminina em nossa profissão tem sido destacada em várias pesquisas (Achcar, 1994; Bastos, \& Gondim, 2010; Conselho Federal de Psicologia, 1988; Lhullier, 2013). A mais recente, de 2013, elaborada pelo Conselho Federal de Psicologia, aponta que $88 \%$ dos 232 mil profissionais atualmente em exercício são mulheres e, neste universo, apenas $4 \%$ citaram universidades como o local em que exercem sua atividade principal como psicólogas. Consideramos como curioso o fato de que, em um cargo administrativo, nossos dados de pesquisa em Minas
Gerais não corroboraram os dados nacionais de gênero em relação à profissão, mas se relacionaram com dados relacionados à ocupação de altos cargos: "É crescente a participação feminina, particularmente nas profissões de nível superior das ciências e das artes $7,9 \%$ em 1998, 8,3\% em 2002 e 9,5\% em 2007) e, embora menos expressiva, em cargos dirigentes como membros superiores do poder público, gerentes e diretores de empresas (de 3,5\% em 1998 para 4,2\% em 2007)" (Fundação Carlos Chagas $\left.{ }^{7}, 2013\right)$.

Usualmente, quando tratamos de ocupações de nível superior, voltamo-nos para a formação inicial, e, posteriormente, para a formação continuada ou em serviço. Como estas questões podem ser pensadas no caso de coordenadores de curso? A área em que o coordenador se formou e atua faz diferença em relação às tarefas da coordenação? Por exemplo, se ele tem experiência na área de Recursos Humanos ou de Educação, esta experiência poderia auxiliá-lo na coordenação? Pensamos que não necessariamente, pois a formação inicial pode colaborar no sentido de fornecer elementos teóricos e práticos para a compreensão acerca das relações pessoais e institucionais que compõem a IES, mas não prepara a pessoa para todos os desafios que o cargo exige, apresentados pelos participantes e discutidos ao longo deste artigo.

A função de coordenação envolve tarefas específicas, tanto acadêmicas e científicas quanto administrativas e segundo Camargos et al. (2010), é "uma atividade complexa e trabalhosa, em muitos casos exaustiva" (p. 287). Outro aspecto importante levantado e que precisa ser considerado em relação a este cargo:

\footnotetext{
um elevado grau de competência técnica e científica na área de conhecimento do curso por parte de quem a exerce, preparo para trabalhar com o ensino de nível superior e apoio de um colegiado cuja missão é deliberar com o coordenador sobre as melhores propostas para o contínuo melhoramento do curso (Camargos et al., 2010, p. 287).
}

Uma pesquisa sobre a atuação e as condições de trabalho de coordenadores de cursos de Administração do Estado de Minas Gerais foi realizada por Camargos et al. (2010). Entre vários aspectos, ressaltamos alguns

6. Nas instituições públicas pesquisadas, os mandatos dos coordenadores de curso são de dois anos, podendo haver uma recondução seguida. Nas privadas não há um prazo estabelecido.

7. Lugar das mulheres no mercado de trabalho: setores de atividade e estrutura ocupacional. Recuperado de http://www.fcc.org.br/ bdmulheres/serie4.php?area=series 


\section{da Silva, Silvia Maria Cintra; Peretta, Anabela Almeida Costa e Santos; Silva, Larice Santos; Nasciutti, Fabiana Marques Barbosa; Naves, Flaviana Franco; Lima, Nayara Portilho (2016). Formação do}

Psicólogo: Concepções de Coordenadores.

relativos especificamente à função de coordenação, que podem ser pensados também no caso de cursos de Psicologia: a gestão do trabalho administrativo; a coordenação das disciplinas, no que se refere à questão curricular; a coordenação pedagógica, que envolve a qualidade da dimensão acadêmica (Camargos et al., 2010).

O envolvimento com questões administrativas foi abordado por vários coordenadores, e escolhemos o trecho abaixo para exemplificar: "Você entra no negócio achando que vai fazer alguma coisa, fazer uma gestão, poder estudar todo o projeto pedagógico, as diretrizes. Só que cai num emaranhado de atribuições de ordem administrativas, funcionais, $R H$, professor, aluno e vai ficando envolvido" (IES $3^{8}$ ).

Somente um dos coordenadores - embora com pouco tempo na instituição - já havia exercido a função anteriormente, experiência que o auxiliou nas atividades atuais. É inevitável que nos cursos existam docentes com diferentes experiências profissionais, tempo de formação, tempo na instituição, conhecimento acerca do projeto pedagógico e das Diretrizes. Nesse caso, é importante que o colegiado de curso, que apoia e trabalha diretamente com o coordenador, apresente uma constituição que contemple essa diversidade. Além do apoio ao coordenador, a vivência no colegiado de curso pode funcionar como uma espécie de estágio em relação à coordenação, pois nesse lugar é possível conhecer mais de perto as várias funções que aquele precisa desempenhar.

Qual o tempo ideal para exercer a função de coordenador? Considerando-se que não há uma formação inicial específica (no máximo há uma experiência com questões da coordenação por meio da participação no colegiado), mas somente o aprendizado no próprio exercício profissional cotidiano, talvez seja interessante pensar-se sobre qual período seria razoável para a apropriação e execução das atividades do cargo ${ }^{9}$. Uma ideia neste sentido seria que o coordenador futuro, antes de assumir o cargo, pudesse acompanhar o coordenador atual, em uma espécie de "estágio".
Um dos coordenadores, que está no cargo há quatro anos, teve uma experiência anterior durante nove meses, quando ainda estava com menos de um ano de casa. Mesmo que provavelmente tenha se esforçado para exercer a função, consideramos que é necessário um tempo de vivência institucional para que um docente possa se apropriar das normas acadêmicas, do projeto pedagógico, do cotidiano do curso e da cultura universitária para desempenhar a função de coordenador.

Consideramos importante relatar que dois dos seis entrevistados foram contratados com o intuito explícito de ocuparem o cargo de coordenador de curso. Será uma coincidência que em seus discursos eles mostrem-se conhecedores de detalhes do funcionamento dos respectivos cursos e um deles profundamente informado a respeito das DCN? Provavelmente não, mas isto não significa que a apropriação sobre o projeto pedagógico e as funções do cargo não possa ocorrer de outros modos. Além disto, tal situação é uma especificidade de IES privadas, pois nas públicas os concursos ocorrem somente para o cargo de docente.

\section{Caracterização dos cursos de Psicologia}

Esta categoria refere-se às características dos cursos de Psicologia que fizeram parte da pesquisa. $\mathrm{O}$ curso mais longevo existe há mais de 30 anos e o mais recente, há 12. De modo geral, podemos afirmar que temos dois extremos, neste quesito: três cursos com bastante tempo de funcionamento (mais de 30 anos) e dois mais novos (até 15 anos). Os mais antigos surgiram muito antes das Diretrizes Curriculares de 2004 e, com a promulgação destas, tiveram que se debruçar sobre o documento para realizar as reformulações necessárias. Os outros dois, mais jovens em relação a tais discussões, encontraram mais facilidade nesse processo, já que em ambos nenhuma turma havia se formado em 2004. Isto não significa que não foi preciso efetuar mudanças no projeto pedagógico, mas que não houve tempo para que os respectivos projetos se

8. Nomenclatura utilizada pelas pesquisadoras para garantir o sigilo das instituições e dos participantes, a sigla IES refere-se à Instituição de Ensino Superior e o numeral à ordem de participação destas na pesquisa.

9. Apenas um ex-coordenador citou a Associação Brasileira de Ensino de Psicologia (ABEP), referindo-se a "normativas" lançadas pela entidade e entregues aos docentes. Considerando as várias frentes de trabalho encabeçadas pela ABEP, algumas especificamente dirigidas a coordenadores de curso, acreditamos que o conhecimento a respeito da entidade e a participação em eventos por ela promovidos podem ser de grande auxílio, assim como também podem ser compreendidos como uma espécie de formação continuada no que se refere à coordenação de curso de Psicologia. Criada em 1999, a ABEP "é uma entidade de âmbito nacional, de caráter educacional, que objetiva o desenvolvimento e o aprimoramento do ensino da Psicologia", de acordo com o seu Estatuto (http://www.abepsi.org.br/ site/o-que-e-abep/estatuto-2/). 
cristalizassem, o que, no caso dos cursos mais antigos, acabou gerando dificuldades em relação às alterações postuladas pelas DCN.

Todos os coordenadores avaliam seus respectivos cursos de forma positiva, destacando: o cuidado com a formação do estudante; a capacitação do corpo docente; os projetos e atividades desenvolvidas; o compromisso com a comunidade externa - que valoriza o trabalho realizado pelos estagiários e docentes do curso de Psicologia.

\section{Diretrizes Curriculares Nacionais}

Três entrevistados não vivenciaram a discussão sobre as DCN como coordenadores; um deles acompanhou o processo somente como membro do colegiado. Constatamos que o fato de o coordenador ter participado dessa discussão (às vezes muito longa) e implementação das DCN o auxilia a compreender tanto a presença de determinadas disciplinas e atividades quanto a lógica da matriz curricular. Cada projeto pedagógico tem uma história institucional e é importante que o coordenador se aproprie dela.

Veiga (2008) apresenta reflexões importantes sobre o sentimento de pertença que é provocado quando o projeto político-pedagógico é, efetivamente, construído de forma coletiva: "No plano afetivo, a construção do projeto apresenta efeitos mobilizadores da atividade dos atores implicados, o que gera compromissos e responsabilidades educativas" (p. 16). Nesse sentido, a identidade institucional é elaborada a partir da ação coletiva dos atores que constituem a universidade e, neste processo, também se constituem.

Eu creio que as diretrizes foram boas no sentido de dar um pouco mais de liberdade, eu acho que tem essa coisa de trabalhar com os eixos, grade curricular, outros procedimentos ligados à saúde coletiva que tira essa perspectiva da clínica no consultório, mas de pensar uma coisa mais ampla [...]. Eu acho que favorece muito a possibilidade da composição criativa e ao mesmo tempo mais de acordo com as regiões, com o corpo docente e com as expectativas dos alunos. Eu acho que nenhuma Diretriz se basta. Acho que por mais que a Diretriz queira cuidar, sempre terá coisas que nós podemos questionar, mas eu sinto que em linhas gerais elas (as Diretrizes) deixam muito espaço para o colegiado, para o Núcleo Docente Estruturante definir essas questões (IES 2).
Entre os seis entrevistados, cinco não demonstram amplo conhecimento acerca das Diretrizes; um deles chega mesmo a admitir seu total desconhecimento. Aqui podemos destacar duas instâncias relativas ao conhecimento sobre as DCN: a) informações e reflexões oferecidas pelo curso ao corpo docente; b) esclarecimento e acompanhamento sobre esse debate a partir da própria IES, do Conselho Federal de Psicologia e do Ministério da Educação.

A formação generalista proposta pelas DCN é vista com bons olhos pelos coordenadores, mas temem que as ênfases possam virar especializações, o que os leva a ter algumas ressalvas quanto ao documento. Consideramos que não há uma forma fixa e imutável para a implantação das Diretrizes. Elas precisam ser tratadas como indicações que devem balizar o modo como o curso se estrutura, devem ser analisadas a partir do histórico político-educacional em que foram construídas, considerando-se, por exemplo, marcos como o movimento de democratização de nosso país e a política neoliberal na Educação Superior, bem como o Sistema Nacional de Avaliação do Ensino Superior (SINAES).

Como escrevem Veiga e Araujo (2010, p. 31):

[...] o projeto político-pedagógico significa uma inter-
venção no presente visando o futuro; por outro lado,
implica, pelo próprio fato, uma memória do passado,
seja pela interpretação do cotidiano vivido no decorrer
do processo escolar, sobretudo dentre os professores,
mas nunca desligado da dinâmica intersubjetividade
com os alunos [...] com os gestores; entretanto, todos
eles estão mediados pela sociedade na qual se inserem.

Esta reflexão vai ao encontro da fala deste coordenador: "o nosso cuidado maior na elaboração de projeto político pedagógico de formação de psicólogos foi de não cairmos na armadilha de perpetuar o modelo de formação da Psicologia Clínica tradicional ainda tão em voga entre nós"(IES 3).

De modo geral, podemos afirmar, a partir dos relatos dos coordenadores e do ex-coordenador, que todos os projetos pedagógicos demandaram um grande esforço dos envolvidos na elaboração dos novos caminhos a serem trilhados em cada um dos cursos. Nestes percursos, foi necessário tanto contemplar o que era solicitado pelas DCN quanto respeitar a formação e a experiência dos professores, bem como as especificidades de cada curso, considerando também a realidade brasileira como pano de fundo dessa composição. 


\section{da Silva, Silvia Maria Cintra; Peretta, Anabela Almeida Costa e Santos; Silva, larice Santos; Nasciutti, Fabiana Marques Barbosa; Naves, Flaviana Franco; Lima, Nayara Portilho (2016). Formação do Psicólogo: Concepções de Coordenadores.}

Com a implementação das DCN, os cursos reorganizaram seus projetos pedagógicos e, antes da primeira turma do currículo concluir a graduação, os coordenadores constataram a necessidade de mudanças nesses projetos, procurando adequá-los às demandas surgidas ao longo do processo de implementação. Tais alterações reiteram a necessidade de avaliação permanente do projeto pedagógico, com ajustes que acompanhem o caminhar do curso. As reformulações citadas pelos coordenadores entrevistados também abarcam a estrutura dos cursos e as disciplinas neles oferecidas, reafirmando a importância de o projeto pedagógico ser cuidadosamente acompanhado pela comunidade acadêmica, para que os campos em que cotidianamente ele se concretiza: as salas de aula, a clínica-escola e os demais espaços de estágio, extensão e pesquisa possam apontar tanto necessidades de mudanças quanto de permanência. Como afirma Yamamoto (2000):

As proposições legais [...] reproduzem os conflitos e as contradições presentes nessa formação social específica [...]. A própria forma pela qual a Comissão de Especialistas tratou a questão das Diretrizes Curriculares é uma demonstração disso. Uma vez que se trata de um espaço de conflito, é fundamental estarmos atentos aos desdobramentos da legislação e dispostos aos inevitáveis embates (p. 37).

O seguinte trecho da entrevista de um coordenador ilustra esse processo:

\begin{abstract}
Nós aproveitamos, reorganizamos e reaproximamos mais coisas que tem a ver com a outra, as ementas também vão mudar, então nós vamos ter um anexo ao projeto que dá conta disso. Então acho que fica melhor para visualizar [...] nós temos muita liberdade no projeto pedagógico, ele é o espelho do grupo que está aqui, dos professores, porque ele é montado por meio de discussão com os professores (IES 2).
\end{abstract}

Para Pogetto (1998, p. 66), "construir e implementar o projeto pedagógico é um trabalho permanente, que deve enfatizar a formação como objeto de discussão, intervenção e estudo".

O ex-coordenador faz um apontamento de que muitos professores ainda continuam considerando a divisão anterior em áreas, ao invés de incorporar as ênfases. Em relação ao currículo, houve um aspecto mencionado apenas por um dos coordenadores, mas que consideramos muito importante na discussão e na compreensão acerca de currículos e projetos pedagógicos: "o projeto pedagógico está muito bonito porque ele recebeu/recebe toda uma filosofia que nós queremos imprimir, mas [temos também] o currículo oculto, aquilo que vai acontecendo pelas dificuldades, pelas deformações inclusive"(IES 2, grifos nossos).

Para Giroux e Penna (1997), é imprescindível que a experiência educacional considere a aprendizagem que ocorre por meio do currículo oculto. Esta aprendizagem é tão importante que, em alguns casos, pode chegar até mesmo a minar a aprendizagem prevista e proposta no currículo oficial. Rasera, Balaz e Yazlle (1998) apresentam um artigo sobre o currículo oculto no curso de Psicologia a partir da experiência dos alunos em um Fórum de Debates sobre estágios. Três aspectos foram destacados pelos autores considerando várias situações apresentadas pelos estudantes, que apontaram os modos como o currículo oculto se delineia no dia a dia do curso: a organização dos estágios, a relação entre professores e "a fragmentação do discurso psicológico" (p. 46). Os autores ressaltam, em suas considerações finais, que "frente a tantas mudanças em nossa sociedade, apenas a reflexão compartilhada - sobre a prática profissional, as relações institucionalmente estabelecidas na formação e o conhecimento psicológico - poderá construir um contexto propício ao enfrentamento de tais desafios." (p. 49).

Juntamente com as considerações de Giroux e Penna (1997), é possível pensar na configuração curricular como uma importante possibilidade emancipatória na formação do futuro psicólogo, em que nuances do currículo oculto sejam desveladas para contribuir de modo integrado ao currículo oficial. Além disso, a elaboração do currículo precisa ser pensada considerando-se o perfil do egresso, as condições de formação oferecidas pela IES, a discussão sobre as DCN, os aspectos éticos e o compromisso social envolvidos tanto na formação do futuro psicólogo quanto nos serviços oferecidos à população.

Embora se refiram ao currículo em sua denominação, as DCN não o mencionam em todo o documento. A terminologia usada é "projeto de curso" e a expressão "projeto pedagógico" aparece apenas no Artigo 13, que trata da formação do professor de Psicologia. Segundo Veiga (2008, p. 14),

o projeto político-pedagógico tem a ver com a organização do trabalho pedagógico em dois níveis: como organização da escola como um todo e como organização da 
sala de aula, incluindo sua relação com o contexto social imediato, procurando preservar a noção de totalidade.

Ainda ao tratar do Projeto Político Pedagógico (PPP), Veiga (2011) afirma que é preciso levar em conta três aspectos principais:

\begin{abstract}
1. O projeto é uma antecipação [...] Relaciona-se com um tempo a vir [...] Nesse caso, é o futuro que deve orientar e conduzir nossa ação presente. 2. O projeto tem uma dimensão utópica, que significa, na verdade, o futuro 'a fazer', um possível a se transformar em real, uma ideia a transformar-se em ato. [...] Essa perspectiva reforça o caráter político da educação e valoriza o papel da universidade e do projeto político-pedagógico voltado para o desenvolvimento de um projeto histórico de transformação da ordem social. 3. Por ser uma construção coletiva, o projeto tem efeito mobilizador da atividade dos protagonistas. [...] A participação é um elemento político de ação e até garantia da execução e continuidade das ações (p. 15).
\end{abstract}

Considerando que o currículo vai além de um mero documento escrito, mas se constitui em um processo vivo, inserido nas práticas educativas cotidianas e que direciona a formação, defendemos que a organização curricular, bem como sua efetivação nos cursos de Psicologia é uma das tarefas do coordenador em conjunto com os colegas docentes e a participação dos alunos.

Apresentadas algumas considerações relativas ao currículo, passaremos a discutir a formação do psicólogo.

\section{Formação de psicólogo}

Em relação à concepção de Psicologia, cinco coordenadores apresentam, de modo explícito, uma concepção condizente com os avanços da Psicologia como ciência e profissão nos últimos anos, indicando um olhar que abarca tanto os sujeitos como as instituições em que estes se inserem, como podemos ler neste excerto: "Não tem muito como analisar a instituição sem discutir o sujeito que está ali inserido, da mesma forma não tem como discutir o sujeito sem discutir que instituição é essa na qual ele está inserido" (IES 1).

Esta é uma concepção fundamental para a formação do psicólogo, pois como escreve Bock (2000) é importante que se considere o ser humano a partir de uma

Visão de homem histórico, isto é, um ser constituído no seu movimento; constituído ao longo do tempo, pelas relações sociais, pelas condições sociais e culturais engendradas pela humanidade. Um ser que tem características forjadas pelo tempo, pela sociedade e pelas relações (p. 24).

Vemos também concepções de Psicologia que ultrapassam a visão tradicional do psicólogo clínico e buscam incluir questões institucionais, em uma concepção que insere as políticas públicas, aspecto que hoje pode ser considerado imprescindível - e irreversível - na formação do futuro psicólogo: "clínica ampliada, a gente pensou na clínica enquanto olhar, mais do que o espaço, [mais do que] a questão da psicoterapia" (IES 2). Projetos citados pelos coordenadores, voltados para o Sistema Único de Saúde (SUS) e o CRAS, por exemplo, exemplificam uma concepção de Psicologia comprometida com questões sociais contemporâneas.

Em relação à formação do psicólogo, destacamos, nas entrevistas, recursos didáticos e práticas desenvolvidas nos cursos, tendo as Diretrizes como elemento norteador e também considerando as habilidades e as competências preconizadas no documento. Nos excertos há um tom de crítica em relação ao modo como têm acontecido as avaliações, à configuração do projeto pedagógico e à formação do futuro profissional: “[...] o nosso sistema de avaliação ainda é muito conteudista. Trabalha em cima do conteúdo ministrado em sala de aula e nem sempre nós encontramos maneiras de avaliar que priorizem habilidades e competências" (IES 1). A questão da avaliação do processo de aprendizagem também precisa ser pensada na proposta do projeto pedagógico: “Acontece que o ensino superior tem dificuldade na formação pedagógica do professor, tem uma formação muito técnica e em termos pedagógicos não" (IES 3). Ainda neste sentido:

A ideia era construir um modelo de prova com o aluno em que ele se engajasse, mas vai levar um tempo ainda porque as diferenças se acentuam muito na formação de cada um. A gente vê que os alunos fogem das provas, será que não tem alguma outra forma de avaliá-los? Mas ainda não temos críticas suficientes para fazer essa leitura para poder apontar outros rumos (IES 3).

Qualquer prática pedagógica baseia-se em uma determinada concepção sobre o processo educativo, bem como sobre os processos de ensino-aprendizagem, que consideramos dialeticamente associados. E, como nos lembra Libâneo (apud Cury, 2012, p. 48). 


\section{da Silva, Silvia Maria Cintra; Peretta, Anabela Almeida Costa e Santos; Silva, larice Santos; Nasciutti, Fabiana Marques Barbosa; Naves, Flaviana Franco; Lima, Nayara Portilho (2016). Formação do Psicólogo: Concepções de Coordenadores.}

\begin{abstract}
[...] o planejamento escolar é uma tarefa docente que inclui tanto a previsão das atividades didáticas em termos da sua organização e coordenação em face dos objetivos propostos, quanto a sua revisão e adequação no decorrer do processo de ensino. O planejamento é um meio para se programar as ações docentes, mas é também um momento de pesquisa e reflexão intimamente ligado à avaliação.
\end{abstract}

A afirmação feita pelo coordenador da IES 1 quanto à coerência entre o conteúdo ministrado e os modos de avaliação da aprendizagem do aluno, independentemente das formas como estes modos se apresentem, indica a necessidade de uma coesão em relação à formação do futuro psicólogo, que envolve todos os elementos desta trajetória ao longo do curso. Ainda sobre a avaliação, Cury (2012) traz importantes ponderações, ao considerá-la

Um instrumento por meio do qual se reconheçam os caminhos percorridos e se identifiquem quais são os caminhos que ainda necessitam ser trilhados. Abandona-se, neste modelo, a avaliação como instrumento meramente classificatório, que não serve para a transformação, mas atua em função da conservação da sociedade pela domesticação dos estudantes (p. 63).

Os coordenadores frisam a indissociabilidade entre ensino, pesquisa e extensão ${ }^{10}$; os estágios básicos também são citados como elementos diferenciados na formação do estudante. De modo geral, nenhum coordenador fez críticas sobre competências e habilidades desenvolvidas no curso, como preconizadas pelas Diretrizes, no artigo $8^{\circ}$, que aludem ao desempenho do egresso que domine conhecimentos básicos em Psicologia, sendo capaz de empregá-los em distintas situações que solicitem "a investigação, análise, avaliação, prevenção e atuação em processos psicológicos e psicossociais, e na promoção da qualidade de vida" (Brasil, 2004, p. 206).

\section{Formação do psicólogo para atuação no campo da Educação}

Em relação à formação do psicólogo para atuação no campo da Educação, três coordenadores mencionaram particularidades necessárias para a atuação do psicólogo na seara educacional, embora nenhum deles tenha formação dirigida a este contexto, o que mostra a importância de o coordenador conhecer, mesmo que sem aprofundamento, as possibilidades e necessidades exigidas para a formação em cada uma das ênfases oferecidas pelo curso.

Considerando a presença de uma ênfase no campo educativo dentro do projeto pedagógico, como mencionamos acima, buscamos conhecer as concepções dos coordenadores acerca de Educação e de Psicologia Escolar e Educacional, como podemos ler no excerto:

[...] eu acho que a gente deve quebrar, em termos do curso, quebrar preconceitos porque isso também a Psicologia carrega, de que a Educação é um campo menos nobre, $e$ aí a gente pode também desenvolver o gosto e a responsabilidade pela educação, do quão é importante o papel do psicólogo de estar junto com a questão da educação. [...] então a gente tenta o trabalho de grupo, aprender a trabalhar com grupos porque o papel do psicólogo na educação qual é? De pensar que ele faz intervenção nas relações e não na questão da doença, não é?! Isso não cabe a ele, então que instrumentos ele tem, esse olhar crítico e reflexivo de pensar a instituição como um todo, de recursos para uma análise institucional e poder fazer intervenções grupais, coletivas pensando em todos os elementos que fazem parte do processo da educação (IES 2).

Dois coordenadores afirmam que a formação do futuro psicólogo para trabalhar no campo educativo é singular e, de certo modo, mais exigente do que para a atuação em outras áreas: “[...] no caso especificamente da Educação, eu acho que ele tem que ter uma sensibilidade específica pra esse segmento, é quase que uma afinidade com esse campo para atuar e compreender um pouco as contradições do processo educativo" (IES 3).

Dois coordenadores e o ex-coordenador explicitam uma compreensão mais ampliada sobre os processos de escolarização, chegando a citar a questão atual da medicalização: "Porém, há uma tendência muito médica de olhar para a Educação. [...] os psicopedagogos querem continuar fechando a coisa, numa visão mais... todo mundo está doente hoje, todos somos hiperativos" (IES 3).

O perfil do egresso refere-se à resposta à tradicional pergunta: “Que psicólogo queremos formar?”. Silva (2004) apresenta uma reflexão a respeito do perfil profissional, definido pelos comportamentos que caracterizam eiden-

10. Lembramos que todas as IES participantes da pesquisa são universidades, o que faz com que este tripé seja uma condição inerente para a sua existência e avaliação perante o MEC. bdmulheres/serie4.php?area=series 
tificam as atividades cotidianas de um determinado profissional, ao trazer dois diferentes aspectos, sendo um

\begin{abstract}
[...] idealizado, aquilo que se espera que o profissional saiba fazer, e o outro prático, que é efetivamente o que o profissional faz ou está apto a fazer se necessário, o que também pode ser denominado de "papel" do profissional na sociedade. Assim, é essa capacidade de atuar na sociedade que precisa ser o objeto de trabalho na formação de um profissional (pp. 44-45).
\end{abstract}

Considerando-se a função social da universidade, Goergen (2010), ressalta que a construção de uma sociedade mais justa e democrática depende de indivíduos não só profissionalmente competentes, mas de cidadãos com apurado sentido ético e de responsabilidade social, a universidade, neste caso, deve formar profissionais críticos, autônomos e socialmente responsáveis (p. 21).

Assim, podemos perguntar: que educação os estudantes devem receber no Ensino Superior?

Entendemos que é necessária uma preocupação com a formação geral do estudante, que envolva o entendimento acerca das questões do mundo atual "tanto no contexto próprio de sua vida como nos contextos sociais, culturais, econômicos, políticos mais amplos" (Pereira, 2010, p. 43). Neste sentido, quatro coordenadores consideram que a organização curricular a partir das DCN contribui para uma formação generalista, crítica e ética e dois destacam o compromisso social do estudante de Psicologia.

O coordenador da IES 3 ressalta, em sua entrevista, a necessidade de se "quebrar um pouco essa divisão de teoria e prática". Esta é uma discussão importante que avança no sentido da indissociabilidade entre teoria e prática, o que na configuração curricular anterior às Diretrizes de 2004 não ocorria devido à organização denominada " $4+1$ ", ou seja, quatro anos de fundamentação teórica e um ano, o último do curso, de vivência da prática. Como escreve Tanamachi (1997):

Não é da teoria que se extrai a ação, mas é a importância da ação no interior de uma determinada realidade que permite integrar e adequar os instrumentos elaborados por diferentes correntes teóricas (que expressam e contêm as concepções teóricas que os fizeram surgir) aos propósitos e finalidades de apreensão/explicação dos fenômenos da realidade (p. 136).
Sabemos, entretanto, que o oferecimento de estágio básico nos períodos iniciais do curso não basta para que haja, efetivamente, uma integração entre as dimensões prática e teórica, seja na compreensão dos estudantes sobre estes aspectos, seja na forma como este estágio lhes será apresentado. É fundamental que professores e supervisores de estágio também consigam estabelecer tal compreensão. Os coordenadores destacam os estágios como elemento fundamental para a formação que possa contemplar questões apresentadas pelas DCN, como podemos ler no excerto abaixo:

Que o aluno possa passar por experiências diversas $d u$ rante toda a formação e principalmente nos estágios que eu acho que é ponto alto do curso, trabalhar e que possam então nessas experiências ter uma visão da realidade, de análise dessa realidade e tentar ver se eles se comprometem um pouco com essas questões [sociais] (IES 2).

Quatro coordenadores enfatizam a necessidade de o futuro psicólogo formar-se no contexto educacional, tendo a possibilidade de, nos estágios, terem experiências em contextos coletivos. Como escreve Guzzo (2011) "A formação para a prática diante de um cenário de desigualdades sociais deve levar em conta uma leitura crítica do que significa o cotidiano e a constituição subjetiva nestes contextos" (p. 257). Ainda nesse texto, a autora faz severas críticas à formação de psicólogos para a realidade de nosso país, referindo-se ao seu caráter muitas vezes despolitizado e acrítico.

Um coordenador toca em um tema importante: a formação do estudante para atuar tanto na rede pública quanto na particular. Em algumas cidades brasileiras, não existe o cargo para psicólogo escolar na rede pública de ensino (Souza, \& Silva, 2009; Silva et al. 2012) e, muitas vezes, ao longo do curso, o estudante tem contato apenas com escolas públicas.

É fundamental que o estudante possa compreender especificidades advindas do campo educacional, tanto no que diz respeito ao contexto sócio-político-econômico quanto no que se refere à dimensão subjetiva dos sujeitos que são constituídos ao mesmo tempo em que constituem os espaços educacionais. Além disso, o estudante não pode prever em que campo irá atuar e há vários conteúdos, reflexões teórico-práticas e discussões pertinentes à formação do psicólogo de modo geral e ampliado que não se restringem a ênfases específicas, sendo importantes para a formação em qualquer campo. Isso indica a 


\section{da Silva, Silvia Maria Cintra; Peretta, Anabela Almeida Costa e Santos; Silva, larice Santos; Nasciutti, Fabiana Marques Barbosa; Naves, Flaviana Franco; Lima, Nayara Portilho (2016). Formação do Psicólogo: Concepções de Coordenadores.}

importância de que os conteúdos referentes a cada ênfase possam transitar e dialogar entre si ao longo da formação.

\section{Considerações finais}

Foram identificados diferentes modos de ingresso no cargo de coordenador de curso de Psicologia, nas trajetórias profissionais e no próprio curso em que trabalham. Percebemos que a apropriação da tarefa de coordenador é, obviamente, um processo, que ocorre no transcorrer do trabalho.

Se por um lado podemos fazer algumas críticas em relação à fragilidade de alguns coordenadores no que se refere às tarefas do cargo, por outro, percebe-se que existem intenções no sentido de realizar um trabalho e que, obviamente, estes trazem para as suas funções as suas concepções pessoais como psicólogos. É claro que, como coordenadores de um curso, isto precisa ser ampliado e há conteúdos necessários para o exercício desta função. Perguntamos, então, o que é imprescindível que o coordenador saiba/conheça?

Fica evidente a necessidade da formação continuada do coordenador de curso, pois apesar de ser uma atividade com grandes contribuições profissionais, esta função pode ser também um obstáculo ao desenvolvimento de outras tarefas acadêmicas, como a realização de pesquisas, a orientação na pós-graduação e outras que demandem maior tempo para a sua execução.

Além do âmbito do próprio curso de graduação, a formação e o apoio aos coordenadores de curso precisam ser considerados no contexto da própria IES. Em artigo sobre os desafios à implementação das Diretrizes nos

\section{Referências}

Achcar, R. (Coord.) (1994). Psicólogo brasileiro: práticas emergentes e desafios para a formação. São Paulo, SP: Casa do Psicólogo.

Barreto, M. A., Calafangel, P. A. F. R. D., \& Lima, Z. P. (2009). Estudo com psicólogos escolares: ações e desafios. Psicologia Argumento, 27(58), 261-269.

Barbosa, F. M. (2013). O processo de ensinar-aprender uma perspectiva crítica em psicologia escolar e educacional: histórias compartilhadas por uma supervisora e uma estagiária (Dissertação de Mestrado). Instituto de Psicologia, Universidade Federal de Uberlândia, Uberlândia, MG.

Bastos, A. V. B., \& Gondim, S. M. G. (2010). (Orgs.) O trabalho do psicólogo no Brasil. Porto Alegre: ARTMED. cursos de Psicologia, Feitosa (1999) aborda a necessidade de uma interlocução entre as coordenações de cursos, a pró-reitoria ou instância análoga de administração e de pós-graduação, considerando a política institucional para a formação de pessoal para atuar no ensino superior.

Como as concepções dos coordenadores a respeito dos seus respectivos cursos, da implementação das DCN, das ênfases e mais especificamente da ênfase relacionada ao campo educativo são apenas uma parte da pesquisa realizada, é fundamental dialogarmos com relatos, informações e reflexões apresentados por estudantes, professores e projetos pedagógicos, para que possamos ter uma visão mais ampliada e fundamentada sobre a formação do psicólogo e do psicólogo para atuar no campo educativo, bem como das repercussões ocasionadas pelas DCN.

Entendemos que esta pesquisa pode ser complementada por outros estudos que também busquem investigar a temática aqui apresentada, ponderando a importante função dos coordenadores de curso para a formação de psicólogos, presente tanto na organização e na implementação do projeto pedagógico como no currículo oculto que se delineia no cotidiano institucional. Ressaltamos que o trabalho do coordenador é fundamental para que o processo de formação do psicólogo se concretize com qualidade, uma vez que suas ações podem contribuir para a articulação entre o currículo e o desenvolvimento cotidiano das atividades educacionais de maneira a mediar a formação de futuros psicólogos para além de meros executores de técnicas, mas como cidadãos comprometidos com as demandas da população brasileira.

Bertucci, J. L. O., \& Moraes, W. B. (2003). Efetividade organizacional na perspectiva de coordenadores de cursos de graduação da Puc Minas. E \& G Economia e Gestão, 3(6), 58-89. Recuperado de http:// periodicos.pucminas.br/index.php/economiaegestao/article/view/96/89

Bock, A. B. M. (2000). As influências do Barão de Münchhausen na Psicologia da Educação. In E. R. Tanamachi, M. P. R. Proença, \& M. E. M. Rocha, Psicologia e educação: desafios teórico-práticos. São Paulo, SP: Casa do Psicólogo.

Bogdan, R. C., \& Biklen, S K. (1994). Investigação qualitativa em educação: uma introdução à teoria e aos métodos. Porto: Editora Porto.

Brasil, Ministério da Educação, Conselho Nacional de Educação (2004). Parecer $n^{\circ}$ 0062, de 19 de fevereiro 
de 2004. Fixa as Diretrizes Curriculares Nacionais para os cursos de graduação em Psicologia. Brasília, DF: o autor.

Camargos, M. A.; Ferreira, A. R., \& Camargos, M. C. S. (2010). Percepção, atuação, autonomia e condições de trabalho de coordenadores do curso de administração de IES do estado de Minas Gerais. Revista de Gestão, 17(3), 285-296.

Chauí, M. A universidadeoperacional. (1999). Recuperado de http://www.outrafrequencia.org/2011/02/ universidade-operacional.html

Conselho Federal de Psicologia (1988). Quem é o psicólogo brasileiro? São Paulo, SP: EDICON.

Cury, D. G. (2012). A relação entre professor e aluno no Ensino Superior vista por meio da reprovação (Dissertação de Mestrado). Universidade Federal de Uberlândia, Uberlândia, MG.

Feitosa, M.A.G. (1999). Desafios para a implantação dos novos currículos de psicologia à luz das diretrizes curriculares. Temas em Psicologia, 7(3), 235-243.

Furtado, O. (2012). 50 anos de psicologia no Brasil: a construção social de uma profissão. Psicologia: Ciência e Profissão, 32(num. esp.), 66-85. doi:10.1590/S1414-98932012000500002

Giroux, H. A., \& Penna, A. N. (1997) Educação social em sala de aula: a dinâmica do currículo oculto. In: $\mathrm{H}$. A. Giroux, Os professores como intelectuais: rumo a uma pedagogia crítica da aprendizagem. Porto Alegre, RS: Artmed.

Goergen, P. (2010). Formação superior: entre o mercado e a cidadania. In: E. M. A. Pereira (Org.), Universidade e currículo: perspectivas de educação geral. Campinas, SP: Mercado de Letras.

Guzzo, R. S. L. (2011) Desafios cotidianos em contextos educativos: a difícil formação de psicólogos para a realidade brasileira. In R. Azzi, \& M. H. T. A. Gianfaldoni, (Org.), Psicologia e educação (Vol. 1, pp. 253-270). São Paulo, SP: Casa do Psicólogo.

Kanan, L. A., \& Zanelli, J. C. (2004). O processo de vinculação de coordenadores de curso com seu trabalho e com a universidade. Anais do $\mathrm{V} \mathrm{Co}$ lóquio Internacional sobre Gestão Universitária na América do Sul. Florianópolis. Recuperado de https://repositorio.ufsc.br/xmlui/bitstream/ handle/123456789/35716/Lilia\%20Aparecida\%20 Kanan\%20-\%20O\%20Processo\%20de\%20Vincula\%C3\%A7\%C3\%A3o.pdf?sequence $=4$

Lima, C. P. (2012). O caminho se faz ao caminhar: propostas de formação para uma atuação crítica em psicologia escolar e educacional (Dissertação de Mestrado). Instituto de Psicologia, Universidade de São Paulo, São Paulo, SP.

Lhullier, L. A. (2013). (Org.). Quem é a psicóloga brasileira? Mulher, psicologia e trabalho. Brasília, DF: Conselho Federal de Psicologia.

Marra, A. V., \& Melo, M. C. O. L. (2003). Docente-gerente: $\mathrm{O}$ cotidiano de chefes de departamento e coordenadores em uma universidade federal. In: 270 Encontro Nacional da Associação dos Programas de Pós-Graduação em Administração - ENANPAD, Atibaia. Recuperado de http://www.anpad.org.br/diversos/ trabalhos/EnANPAD/enanpad_2003/GRT/2003_ GRT1135.pdf

Meira, M. E. M. (2003). Construindo uma concepção crítica de psicologia escolar: contribuições da pedagogia histórico-crítica e da psicologia sócio-histórica. In: M. E. M. Meira, \& M. A. M. Antunes, Psicologia escolar. teorias críticas (pp. 13-77). São Paulo, SP: Casa do Psicólogo.

Pereira, E. M. A. (2010). Reforma curricular da Universidade Harvard: a centralização da educação geral no século XXI. In E. M. A. Pereira, (Org.), Universidade e currículo: perspectivas de educação geral (pp. 41-64). Campinas, SP, Mercado de Letras.

Pogetto, M. T. D. P. D. (1998). O projeto pedagógico do Curso de Psicologia da Universidade Metodista de Piracicaba: realidade e perspectivas. Temas em Psicologia, 6(1), 59-67.

Rangel, M. (2001). Coordenação para qualidade dos cursos: repensando conceitos e competências. Olho Mágico, 8(3). Recuperado de http://www. ccs.uel.br/olhomagico/v8n3/especial.htm

Rasera, E. F.; Balaz, F. M. S., \& Yazlle, C. H. D. (1998). O currículo oculto em psicologia: a experiência dos alunos. Temas em Psicologia, 6(1), 45-50. Recuperado de http://pepsic.bvsalud.org/scielo.php?pi$\mathrm{d}=\mathrm{S} 1413-389 X 1998000100005 \&$ script=sci_arttext

Silva, A. L. P. (2004). Desenvolvimento de comportamentos profissionais de avaliação em psicologia na formação de psicólogo (Dissertação de Mestrado). Programa de Pós-graduação em Psicologia da Universidade Federal de Santa Catarina, Florianópolis, SC.

Silva, M. G. R. (2002). Competências gerenciais dos coordenadores/orientadores do Curso de Graduação em Administração de Empresas: um estudo de caso na Universidade de Caxias do Sul (Dissertação de 
da Silva, Silvia Maria Cintra; Peretta, Anabela Alumeida Costa e Santos; Silva, Larice Santos; Nasciutti, Fabiana Marques Barbosa; Naves, Flaviana Franco; Lima, Nayara Portilho (2016). Formação do Psicólogo: Concepcóes de Coordenadores.

Mestrado). Universidade Federal do Rio Grande do Sul, Porto Alegre, RS.

Silva, S. M. C., Lima, C. P., Silva A. C., Rezende, P.C. M., Carrijo, R. S., Ribeiro, M. J., ... Barreto, V. S. (2012). O psicólogo diante da demanda escolar: concepções e práticas no Estado de Minas Gerais. Gerais: Revista Interinstitucional de Psicologia, 5(1), 36-49.

Silva, S. M. C., Pedro, L. G., Silva, D., Rezende, D., \& Barbosa, L. M. (2013). Estágio em psicologia escolar e arte: contribuições para a formação do psicólogo. Psicologia: Ciência \& Profissão, 33(4), 1014-1027.

Silva Neto, W. M. F. (2014) Supervisão de estágio em psicologia escolar: contribuições da psicologia crítica à formação e à prática do supervisor (Tese de Doutorado). Instituto de Psicologia, Pontifícia Universidade Católica de Campinas, Campinas, SP.

Souza, M. P. R. (2009). Psicologia escolar e educacional em busca de novas perspectivas. Psicologia Escolar e Educacional, 13(1), 179-182. doi:10.1590/S1413-85572009000100021

Souza, M. P. R., \& Silva, S. M. C. (2009) A atuação do psicólogo na rede pública de educação frente à demanda escolar: concepções, práticas e inovações. In: C. M. M. Araujo (Org.), Psicologia escolar: novos cenários, formação e prática (pp. 75-105). Campinas, SP: Alínea.

Tanamachi, E. R. (1997). Visão crítica de educação e de psicologia: elementos para a construção de uma visão crítica de psicologia escolar (Tese de Doutorado). Universidade Estadual de São Paulo, Marília, SP.

Veiga, I. P. A. (2008). Projeto político pedagógico da escola: uma construção coletiva. In: Projeto político pedagógico da escola: uma construção possivel (24a ed.). Campinas, SP: Papirus.

Veiga, I. P. A., \& Araujo, J. C. S. (2010). O projeto político-pedagógico: um guia para a formação humana. In I. P. A. Veiga (Org.), Quem sabe faz a hora de construir o projeto político-pedagógico. Campinas, SP: Papirus.

Veiga, I. P. A. (2011). Educação básica e educação superior: projeto político-pedagógico (6a ed.). Campinas, SP: Papirus.

Yamamoto, O. H. (2000). A LDB e a psicologia. Psicologia Ciência e Profissão, 20(4), 30-37. doi:10.1590/S1414-98932000000400004

\section{Silvia Maria Cintra da Silva}

Doutora em Educação pela Universidade Estadual de Campinas, Campinas - SP, Brasil. Docente da Universidade Federal de Uberlândia, Uberlândia MG. Brasil.

E-mail: silvia_ufu@hotmail.com

\section{Anabela Almeida Costa e Santos Peretta}

Doutora em Psicologia Escolar e do Desenvolvimento Humano pela Universidade de São Paulo, São Paulo - SP, Brasil. Docente da Universidade Federal de Uberlândia, Uberlândia-MG. Brasil.

E-mail:anabelaacs@gmail.com

\section{Larice Santos Silva}

Mestranda pela Universidade Federal de Uberlândia, Uberlândia-MG. Brasil.

E-mail: laricesantos@yahoo.com.br

\section{Fabiana Marques Barbosa Nasciutti} Doutoranda pela Universidade Estadual de Campinas, Campinas - SP. Brasil.

E-mail: fabi.marquesb@hotmail.com

\section{Flaviana Franco Naves}

Mestre pela Universidade Federal de Uberlândia, Uberlândia-MG. Brasil.

E-mail: flavinaves@yahoo.com

\section{Nayara Portilho Lima}

Graduada pela Universidade Federal de Uberlândia, Uberlândia-MG. Brasil.

E-mail: naportilho@gmail.com

\section{Endereço para envio de correspondência:}

Universidade Federal de Uberlândia, Instituto de Psicologia, Av. Pará 1720 Bloco 2C, Umuarama. CEP: 38405-320. Uberlândia - MG. Brasil.

Recebido 19/07/2014

Aprovado 20/01/2016

Received 07/ 19/2014

Approved 01/20/2016

Recibido 19/07/2014

Aceptado 20/01/2016 
Como citar: Silva, S. M. C., Peretta, A. A. C. S., Silva, L. S., Nasciutti, F. M. B., Naves, F. F., \& Lima, N. P. (2016). Formação do Psicólogo para Atuar na Educação: Concepções de Coordenadores de Curso. Psicologia: Ciência e Profissão, 36(1): 48-62. doi:10.1590/1982-3703001082014

How to cite: Silva, S. M. C., Peretta, A. A. C. S., Silva, L. S., Nasciutti, F. M. B., Naves, F. F., \& Lima, N. P. (2016). Training of Psychologists to Work in Education - Conceptions of Program Coordinators. Psicologia: Ciência e Profissão, 36(1): 48-62. doi:10.1590/1982-3703001082014

Cómo citar: Silva, S. M. C., Peretta, A. A. C. S., Silva, L. S., Nasciutti, F. M. B., Naves, F. F., \& Lima, N. P. (2016). Formación de Psicólogos para Trabajar en el Ámbito de la Educación - Concepciones de los Coordinadores del Curso. Psicologia: Ciência e Profissão, 36(1): 48-62. doi:10.1590/1982-3703001082014 